\title{
Interventions for improving pharmacist-led patient counselling in the community setting: a systematic review
}

\author{
Sinaa Al Aqeel ${ }^{1 *}$ D, Norah Abanmy ${ }^{1}$, Hiba AlShaya ${ }^{1}$ and Albatoul Almeshari ${ }^{2}$
}

\begin{abstract}
Background: Pharmacist counselling is an important service that has been associated with improved outcomes. The primary aim of this review was to identify, describe, and determine the effectiveness of interventions for improving the counselling practice of community pharmacists.

Methods: We searched PubMed (from January 1990 to June 2017) and the Cochrane Library (June 2017). To supplement our database searches, we searched Google Scholar for papers that cited the identified studies. We included only studies that reported the impact of the intervention on pharmacists' behaviour during counselling. We searched for data from studies with randomised trials, non-randomised trials, controlled before-after studies, or interrupted time series study designs. Parameters including selection bias, performance bias, detection bias, and attrition bias were assessed. The data were narratively synthesised.

Results: We screened 2335 abstracts and 59 full-text articles and included 17 RCTs. Overall, three studies were determined to have a high risk of bias, and 14 studies were determined to have an unclear risk of bias. Fifteen studies investigated multifaceted interventions that included two or more components. The most commonly used interventions were educational meetings $(n=14)$, educational materials $(n=9)$, educational outreach visits $(n=5)$, feedback $(n=5)$, guidelines $(n=5)$, and local opinion leaders $(n=2)$. Outcomes were measured using simulated patient visits $(n=10)$, and the self-reported outcomes of patient or pharmacists $(n=6)$. Most of the included studies $(n=11)$ reported some degree of improvement in counselling practices.

Conclusions: The included studies showed that educational meetings combined with educational materials, outreach visits, and feedback can improve pharmacist counselling in community settings. However, the unclear risk of bias and poor quality of reporting intervention components necessitate caution in interpreting the findings. Recommendations for future studies based on the evidence gap identified in this review are presented.
\end{abstract}

Keywords: Community pharmacy, Community pharmacy services, Pharmacies, Professional practice, Patient education, Counselling

\section{Background}

According to the Joint International Pharmaceutical Federation (FIP)/World Health Organization (WHO) guidelines for good pharmacy practice, the mission of pharmacy practice is to "contribute to health improvement and to help patients with health problems to make the best use of their medicines" [1]. Pharmacist-led

\footnotetext{
* Correspondence: salageel@ksu.edu.sa

${ }^{1}$ Clinical Pharmacy Department, College of Pharmacy, King Saud University,

Riyadh, Kingdom of Saudi Arabia

Full list of author information is available at the end of the article
}

counselling is an important service that has been associated with improved clinical outcomes, quality of life, drug/ disease knowledge, satisfaction, and reduced health service utilisation among patients [2].

There is no accepted definition of counselling. According to Puspitasari et al. [3], researchers either operationally define counselling or refer to specific counselling guidelines in the literature. Pharmacy researchers operationally define counselling as giving advice or providing information on medications, while others focus more on the goal of counselling, i.e. ensuring that patients understand the optimal 
use of medications to improve their quality of life [3]. In a review focusing on the conceptualisation and measurement of pharmacist-patient communication, Shah and Chewning [4] discuss the differences in counselling definitions between the professional counselling literature and other published pharmacy literature. The professional counselling literature, represented by an international interdisciplinary journal, defines counselling as an "individualised process involving guidance and collaborative problem solving to help the patient better manage their health problems" [5], while other published pharmacy literature uses the term "counselling" to refer to the provision of information regarding how to take the drug product properly [4]. Furthermore, the terms "communication", "counselling", "education", and "information provision" have been used interchangeably in the literature, disregarding subtle differences in their meaning [4]. Patient education, for example, is defined as "a planned learning experience using a combination of methods such as teaching, counselling, and behaviour modification techniques that influence patients knowledge and behaviour" [5]. Thus, according to this definition, counselling is an aspect of patient education [4].

In addition to dispensing prescription and nonprescription medications, community pharmacists have great potential to be the first contact for patients seeking treatment for minor ailments. Community pharmacists also have an increasing role in public health through the promotion of healthy lifestyles. Pharmacist-patient interactions in the community setting may also address diet, device use, exercise, referrals, or other non-medication issues. The community setting offers many advantages, such as long opening hours, accessibility, and familiarity.

Studies investigating the counselling practices of community pharmacists have indicated that their elicitation of information prior to supplying medicine, detection of drug interactions, and counselling content are of suboptimal quality [6-11]. Counselling in a community setting is a complex process [12], which may explain the poor quality of community counselling practices.

Previous reviews have examined the impact of community pharmacy services, such as counselling, on patient outcomes [2, 13, 14], quality of counselling [10], verbal counselling rates [3], types of information provided during counselling [3], and the conceptualisations, definitions, and measurements of pharmacist-patient communication in the community setting [4]. Few studies, however, have examined interventions to improve community pharmacy services. Patwardhan et al. [15] reviewed literature published up to 2010 on interventions for enhancing community pharmacists' cognitive services, defined as professional services provided by pharmacists to a patient that are either judgemental or educational in nature. Watkins [16] searched six databases up to 2014 for literature on implementation strategies for clinical guidelines to community pharmacy and their impact on the quality of care provided by community pharmacists, such as adherence to recommended practices or guidelines. In December 2017, Seubert et al. [17] published a review of literature published between 2000 and 2017 on interventions aimed at improving communication between consumers and pharmacy personnel during consultations for medicines that are provided without a prescription.

These reviews focused on general cognitive services rather than on counselling specifically; on specific interventions, such as guidelines; or on specific groups of medications. To date, however, no systematic reviews have focused on interventions for improving counselling in different situations, including prescription and nonprescription medications, consultations for minor ailments, and health promotion. Given the suboptimal quality of counselling noted earlier, we need to close the gap in knowledge regarding which interventions might lead to optimal counselling in the community setting.

The primary aim of this review was to identify, describe, and determine the effectiveness of interventions for improving the counselling practice of community pharmacists. The secondary aim was to provide recommendations for future studies due to the evidence gap identified in this review. In this review, "counselling" is used as a broad umbrella term that encompasses all definitions outlined in the background section.

\section{Methods}

\section{Study design}

The review was guided by the recommendations of the Cochrane Handbook [18] and York Systematic Review Centre for Reviews and Disseminations (CRD) guidelines [19]. The reporting of the review complied with the Preferred Reporting Items for Systematic Reviews and Meta-Analyses (PRISMA) statement [20]. The protocol was not registered on PROSPERO.

\section{Search methods}

We searched PubMed from January 1990 to June 2017. We limited our search to fully published articles written in the English language. The time and language restrictions were due to resource limitations. The Cochrane Library was also searched, including the Cochrane Central Register of Controlled Trials (CENTRAL), the Health Technology Assessment Database, the National Health Service (NHS) Economic Evaluation Database, and the Cochrane Group's specialised register (including the Cochrane Effective Practice and Organisation of Care (EPOC) group register).

The search strategies comprised the following three key concepts: study design, community pharmacy setting, and counselling. The search strategies were designed specifically 
for each concept and were guided by similar previous studies $[2,3,13]$ and combined. The terms used to search the databases are listed in Table 1 . The search was conducted in June 2017. To supplement the results of the online searches, we searched for articles that cited the identified studies using Google Scholar and screened these articles for potential studies. We also screened the bibliographies of the identified studies. We did not search for grey literature, such as conference abstracts and reports, as the lack of details regarding study design would not allow for risk of bias and quality assessments.

\section{Study selection \\ Types of participants}

Studies were eligible for inclusion if they included pharmacists who delivered services in a community pharmacy. The community pharmacy was defined as a pharmacy in the community that is accessible to all and not based in a hospital or clinic or online [5]. As the review question focus on pharmacists, we excluded studies solely targeting pharmacy technicians and studies assessing pharmacy students' counselling skills.

\section{Types of interventions}

We included all types of interventions intended to improve pharmacist-led counselling in a community pharmacy setting. The review aim was to identify the types of interventions examined in the literature; therefore, we imposed no restrictions on the characteristics of interventions, such as mode of delivery (e.g. face-to-face, online), format, frequency, or length.

\section{Type of comparison}

Control groups should have received no intervention, a different intervention, or "usual care" as defined by the individual study's authors.

\section{Types of outcomes}

We included only studies that measured the impact of the intervention on the pharmacists' behaviour during counselling, such as asking questions, providing information, or dispensing appropriate medication. Therefore, we excluded studies that measured pharmacists' satisfaction, attitudes, or theoretical knowledge after the intervention. We also excluded studies that measured only the feasibility or acceptance of an intervention without reporting the impact of the intervention on counselling practices. Studies that examined the impact of counselling on patient outcomes only and did not report outcomes related to the pharmacists' counselling practice were excluded. One such example is a study that reported the impact of a hypertension management programme delivered by community pharmacists on hypertension control, adherence to prescribed regimens, and quality of life.

\section{Types of studies}

We searched for data from studies with randomised trials, non-randomised trials, controlled before-after studies, or interrupted time series study designs as defined in the Cochrane Effective Practice and Organisation of Care (EPOC) guidelines [21]. We did not include other study designs because they provide little, if any, reliable evidence of the effects of interventions.

\section{Data collection}

Two authors independently screened the titles and abstracts of identified citations for potential eligibility using a standardised screening guide. Full articles were retrieved for all studies that appeared to be eligible for inclusion in the review and any studies for which it was not possible to draw firm conclusions regarding eligibility based on the abstract alone. Then, two authors (SA and NA) read the full texts of the potential papers to

Table 1 Search strategy

\begin{tabular}{|c|c|c|}
\hline Database & Search terms & Hits \\
\hline PubMed & $\begin{array}{l}\text { Counseling"[Mesh] OR Counseling OR Counselling OR Counsel* OR "Patient Education as Topic"[Mesh]) OR Patient Education) } \\
\text { OR consult*OR interact* OR advi* AND Community pharmacy OR "Community Pharmacy Services"[Mesh] OR independent } \\
\text { pharmacies OR retail pharmacy OR retail pharmacies OR chain pharmacy OR chain pharmacies) AND Pharmacy[MeSH Major } \\
\text { Topic]) OR "Pharmacy"[Mesh] OR "Pharmacies"[Mesh]) OR pharmacists OR "Pharmacists"[Mesh] OR pharmacies AND Randomized } \\
\text { Controlled Trial OR Controlled Clinical Trial OR Comparative Study OR intervention studies OR time adj series OR pre test OR } \\
\text { pretest OR posttest OR post test) OR impact OR chang* OR evaluat* OR intervention OR random allocation OR evaluation } \\
\text { studies Filters: Publication date from 1990/01/01 to 2017/06/07; English }\end{array}$ & 979 \\
\hline $\begin{array}{l}\text { Cochrane } \\
\text { Library }\end{array}$ & $\begin{array}{l}\text { Counseling or Counselling or Counsel or Advice or Education AND community Pharmacist or community Pharmacists or } \\
\text { community Pharmacy or community Pharmacies }\end{array}$ & 638 \\
\hline \multicolumn{2}{|c|}{ Cochrane Database of Systematic Reviews } & 200 \\
\hline \multicolumn{2}{|c|}{ Cochrane Central Register of Controlled Trials } & 415 \\
\hline \multicolumn{2}{|c|}{ Health Technology Assessment Database } & 1 \\
\hline \multicolumn{2}{|c|}{ NHS Economic Evaluation Database } & 22 \\
\hline
\end{tabular}


confirm whether they satisfied the inclusion criteria. Disagreement was solved by consensus.

The data extraction was performed by a single author (SA) using a data-extraction instrument that encompassed the author, year of the study, setting, participants, sample size, intervention assessed, outcome measures, and main findings. The interventions were grouped according to the EPOC taxonomy of interventions [21], which includes the following four main domains of interventions: delivery arrangements, financial arrangements, governance arrangements, and implementation strategies. Other authors (NA, HA, AA) reviewed the extracted data.

\section{Risk of bias}

The risk of bias for all included studies was independently assessed using the domains suggested by EPOC [21] to assess the risk of bias: random sequence generation, allocation concealment, incomplete outcome data, knowledge of the allocated interventions adequately prevented during the study, protection against contamination, selective outcome reporting, similar baseline outcome measurements, and similar baseline characteristics, and other outcomes.
Then, we summarised the assessments of the risk of bias across domains for each study. An overall rating of low risk of bias was assigned if a low risk of bias was scored for all key domains. An overall rating of high risk of bias was assigned if a high risk of bias was scored for one or more key domains. An overall rating of unclear risk of bias was assigned if an unclear risk of bias was scored for one or more key domains.

\section{Data synthesis}

The data were narratively synthesised due to the profound methodological heterogeneity. The guidelines for narrative synthesis in systematic reviews provided by the York Systematic Review Centre for Reviews and Disseminations (CRD) were followed [19].

\section{Results}

\section{Study selection}

The PRISMA flow diagram of study inclusion and the PRISMA checklist are provided in Fig. 1 and Additional file 1, respectively. The initial search yielded 2335 citations. Based on the abstracts and titles, 2276

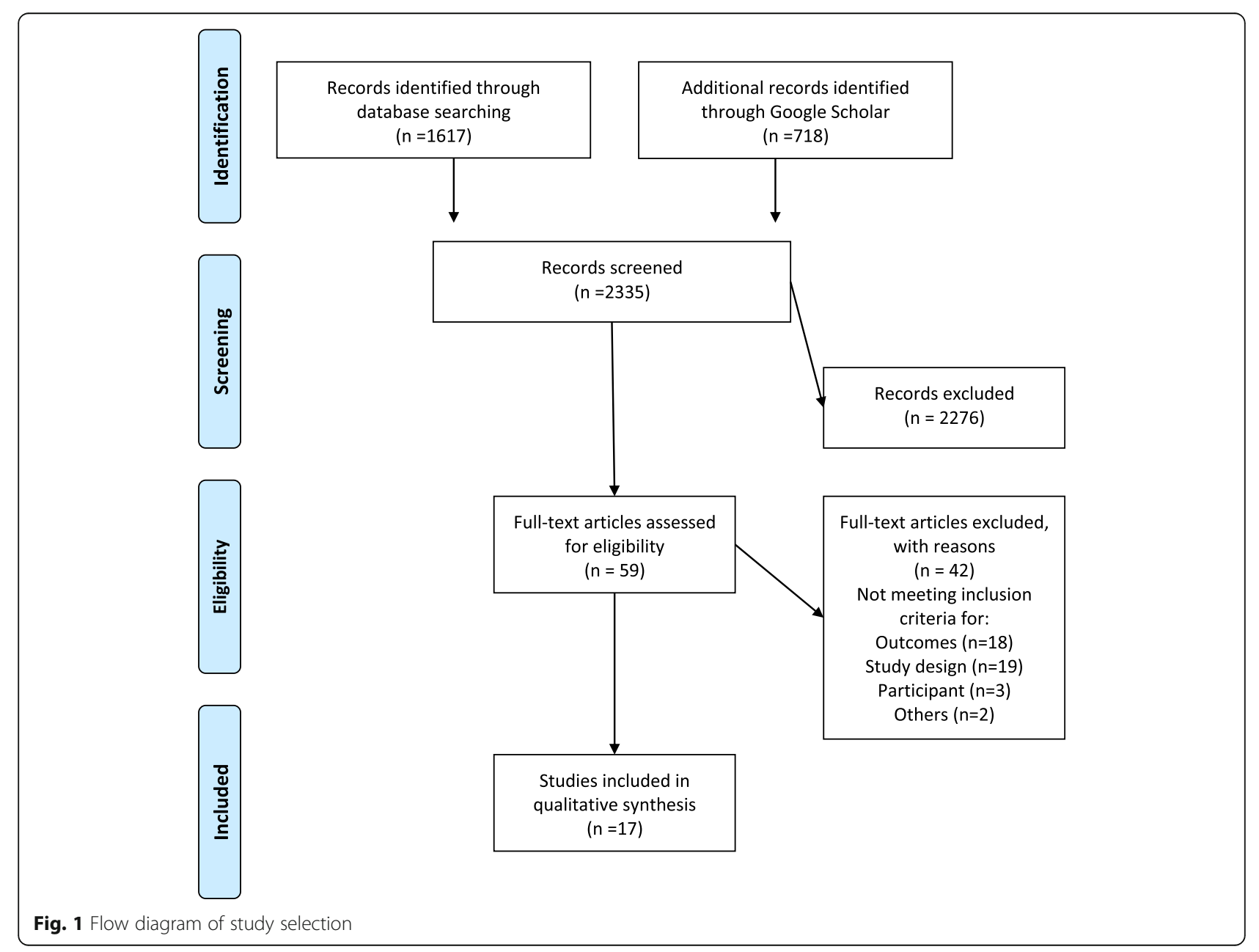


papers were excluded. The remaining 59 articles were retrieved in full text and reviewed, and 42 articles were excluded. Additional file 2 lists articles and reason for exclusions. In total, 17 papers met the inclusion criteria and were reviewed for this paper [22-38]. No additional references were identified by searching the bibliographies.

\section{Characteristics of the included studies}

The characteristics of the included studies are described in Table 2. All included studies used randomised trial designs. The unit of randomisation was either pharmacists, pharmacies, or districts. In total, 16 studies included in this review were at least 10 years old. Four studies were conducted in Australia, four studies were conducted in the USA, two studies each were conducted in Canada, Scotland, Peru, and Vietnam, and one study was conducted in Switzerland.

Only seven studies reported the sample size calculations [22, 24, 27, 35-38]. Twelve studies achieved follow-up with $\geq 90 \%$ of the participants; three studies achieved follow-up with $80-90 \%$ of the participants; and in two studies, the follow-up was less than $80 \%$ (see Table 2).

\section{Risk of bias}

The risk of bias is presented in Table 3. Overall, three studies were determined to have a high risk of bias, and 14 studies were determined to have an unclear risk of bias.

In 11 studies, allocation was by pharmacies, community, or district, and it is unlikely that the control group received the intervention; therefore, the risk of contamination was scored low. In seven studies, the authors explicitly stated that the main outcomes were assessed blindly; therefore, the likelihood of detection bias was low. In four studies, the outcomes were extracted from the participating pharmacists' documentation and thus were judged as unblinded assessments with a high risk of detection bias. We assessed that missing outcome data were unlikely to be related to the true outcome (most commonly, closure of the pharmacy) and that the reasons for missing data were similar across groups. Therefore, we assessed the attrition bias risk as low. In 17 studies, we judged that there was no evidence that outcomes were selectively reported as all the relevant outcomes in the "Methods" section were reported in the "Results" section; hence, the risk of bias from selective outcome reporting was scored as low.

\section{Types of interventions}

All the identified interventions were categorised as implementation strategies (i.e. interventions designed to cause changes in the actions of healthcare organisations, the behaviour of healthcare professionals, or the use of health services by healthcare recipients) [21]. We further grouped these interventions according to the EPOC taxonomy [21] into subcategories, such as educational meetings, educational materials, educational outreach visits, reminders, audits, and feedback. Table 4 presents a definition for each category. As shown in Table 2, 15 studies investigated multifaceted interventions that included two or more components. The most commonly used interventions were educational meetings $(n=14)$, educational materials $(n=9)$, educational outreach visits $(n=5)$, feedback $(n=5)$, guidelines $(n=5)$, and local opinion leaders $(n=2)$. In five studies, pharmacists were supplied with materials to give to patients, such as leaflets, brochures, posters, and prompts, such as sunscreen samples. Additional file 3 provides details on the interventions.

The format, frequency, and length of educational meetings were categorised according to previously used criteria [39]. The format was categorised as either didactic or interactive. The frequency was categorised as frequent (more than 10), moderate (5-10), infrequent (2-4), and one-time only. The length of the educational meeting was categorised as prolonged (5 days or more), moderate (2-4 days), brief (1 day), and very brief (less than 1 day). The majority of the educational meetings were a combination of didactic and interactive formats $(n=13)$, were conducted once $(n=13)$, and were very brief ( $n=14$; see additional file 3$)$. Only six studies indicated the framework used to develop the interventions, including the stages of change model $(n=4)[25,26,36,37]$, the principles of motivational interviewing $(n=2)[25,26]$, cognitive-behavioural and multi-modal therapy $(n=1)$ [30], the social cognitive theory $(n=1)$ [33], and the health belief model [36]. One study described the creation of the intervention in a qualitative study [33]. The control groups received no intervention $(n=12)$ or educational meetings on a different topic $(n=2)$. One study compared the dissemination of an evidence-based guideline via educational meetings, outreach visits, educational and outreach visits, and by post (control) (see Additional file 3).

The costs of the intervention were reported by three studies $[24,29,38]$. The participants' opinions of the intervention were measured in three studies $[31,35,36]$.

\section{Outcome measurement}

The effectiveness of the interventions was measured using a range of outcomes, including changes in pharmacists' behaviour, such as the use of open-ended questions; changes in the number of recommendations made by the pharmacists; and changes in the number of customers who received the service (see Outcome measures in Table 2). 







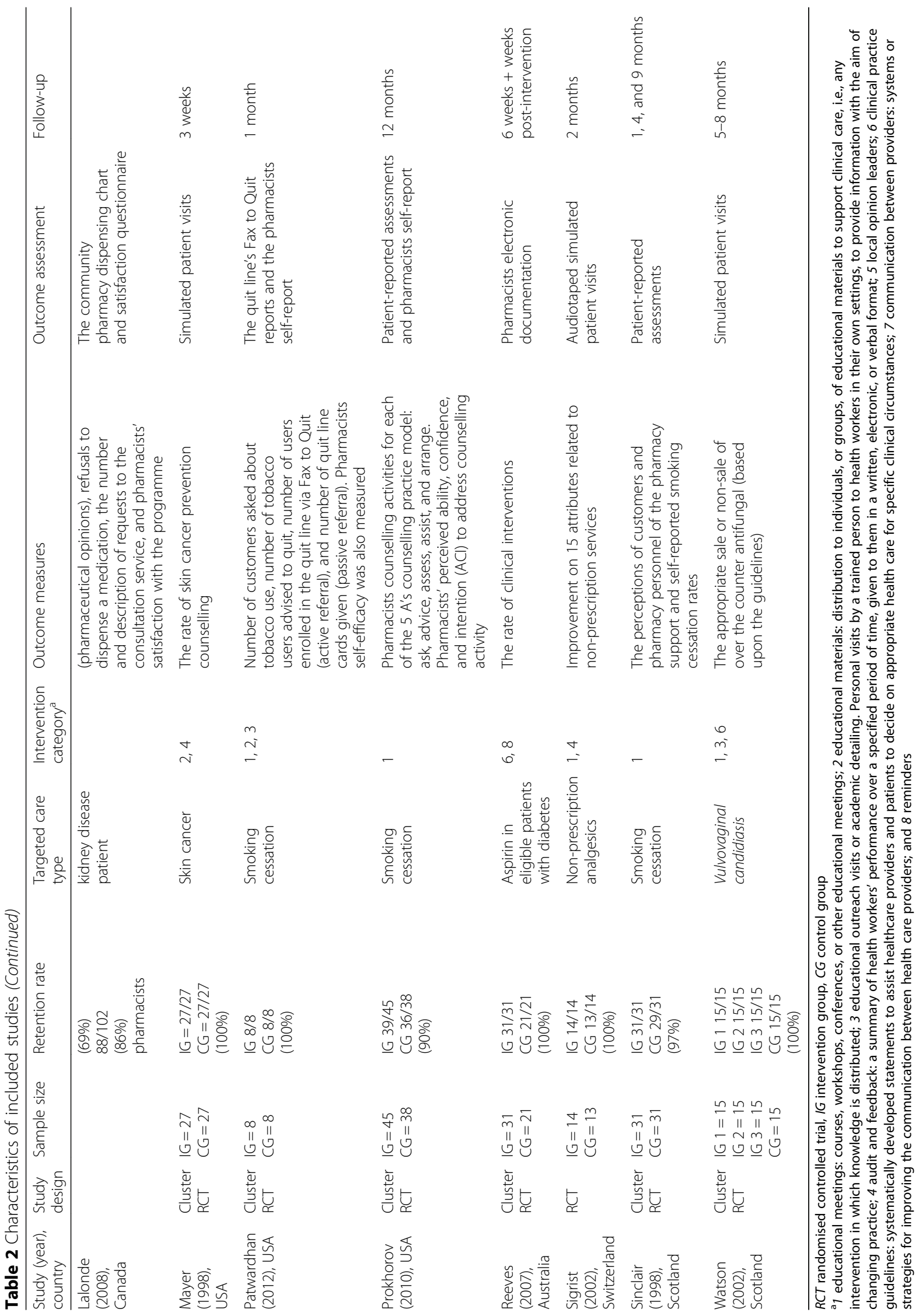


Table 3 Risk of bias of included studies

\begin{tabular}{|c|c|c|c|c|c|c|c|c|c|}
\hline Study (year) & $\begin{array}{l}\text { Was the } \\
\text { allocation } \\
\text { sequence } \\
\text { adequately } \\
\text { generated? }\end{array}$ & $\begin{array}{l}\text { Was } \\
\text { allocation } \\
\text { adequately } \\
\text { concealed? }\end{array}$ & $\begin{array}{l}\text { Was the study } \\
\text { adequately } \\
\text { protected } \\
\text { against } \\
\text { contamination? }\end{array}$ & $\begin{array}{l}\text { Was knowledge } \\
\text { of the allocated } \\
\text { interventions } \\
\text { adequately } \\
\text { prevented? }\end{array}$ & $\begin{array}{l}\text { Were } \\
\text { incomplete } \\
\text { outcome data } \\
\text { adequately } \\
\text { addressed? }\end{array}$ & $\begin{array}{l}\text { Was baseline } \\
\text { outcome } \\
\text { measurement } \\
\text { similar? }\end{array}$ & $\begin{array}{l}\text { Was baseline } \\
\text { characteristics } \\
\text { similar? }\end{array}$ & $\begin{array}{l}\text { Was the } \\
\text { study free } \\
\text { from } \\
\text { selective } \\
\text { outcome } \\
\text { reporting? }\end{array}$ & $\begin{array}{l}\text { Overall } \\
\text { risk }^{\mathrm{a}}\end{array}$ \\
\hline 1. Basheti (2009) & Low & Unclear & Unclear & Unclear & Low & Low & Low & Low & Unclear \\
\hline 2. Chalker (2005) & Unclear & Unclear & Low & Unclear & Low & Low & Unclear & Low & Unclear \\
\hline 3. Chuc (2002) & Low & Unclear & Low & Low & Low & Low & Unclear & Low & Unclear \\
\hline $\begin{array}{l}\text { 4. de Almeida } \\
\text { Neto (2000) }\end{array}$ & Unclear & Unclear & Unclear & Unclear & Low & Unclear & Unclear & Low & Unclear \\
\hline $\begin{array}{l}\text { 5. de Almeida } \\
\text { Neto (2000) }\end{array}$ & Unclear & Unclear & Unclear & Unclear & Low & Unclear & Unclear & Low & Unclear \\
\hline 6. Dolovich (2007) & Low & Unclear & Unclear & Low & Low & Unclear & Low & Low & Unclear \\
\hline 7. Garcia (1998) & Unclear & Unclear & Low & Low & Low & Unclear & Unclear & Low & Unclear \\
\hline 8. Garcia (2003) & Low & Unclear & Low & Low & Low & Unclear & Unclear & Low & Unclear \\
\hline $\begin{array}{l}\text { 9. Kimberlin } \\
\text { (1993) }\end{array}$ & Unclear & Low & Unclear & Unclear & Low & Unclear & Low & Low & Unclear \\
\hline $\begin{array}{l}\text { 10. Lalonde } \\
\text { (2008) }\end{array}$ & Low & Low & Low & High & Low & Low & High & Low & High \\
\hline 11. Mayer (1998) & Unclear & Unclear & Low & Low & Low & Low & Unclear & Low & Unclear \\
\hline $\begin{array}{l}\text { 12. Patwardhan } \\
\text { (2012) }\end{array}$ & Low & Low & Low & Unclear & Low & Low & Low & Low & Unclear \\
\hline $\begin{array}{l}\text { 13. Prokhorov } \\
\text { (2010) }\end{array}$ & Unclear & Unclear & Low & Unclear & Low & Unclear & Low & Low & Unclear \\
\hline 14. Reeves (2007) & Low & Unclear & Low & High & Low & Unclear & Low & Low & High \\
\hline 15. Sigrist (2002) & Unclear & Unclear & Unclear & Low & Low & Low & Unclear & Low & High \\
\hline 16. Sinclair (1998) & High & Unclear & Low & Low & Low & Unclear & Low & Low & Unclear \\
\hline 17. Watson (2002) & Low & Unclear & Low & Unclear & Low & Low & Low & Low & Unclear \\
\hline
\end{tabular}

${ }^{a}$ Key for overall assessment of bias within a study; if low of bias for all key domains (low of bias); if unclear risk of bias for one or more key domains (unclear risk of bias); if high of bias for one or more key domains (high of bias)

The change in outcomes was assessed mainly using simulated patient visits $(n=10$; see Outcome assessment in Table 2). A simulated patient, also known as a standardised patient, pseudo-patient, or mystery shopper, is a patient actor who is trained to simulate pre-determined situations in the course of teaching or evaluation [40]. Self-reports of patient or pharmacists were included as outcomes in four studies. Pharmacists' documentations were reported in three studies. No study reported on the validity and reliability of the tool used to measure outcomes.

The outcome assessments occurred a few weeks after the interventions in most of the identified studies (see Follow-up in Table 2).

\section{Effects of the interventions}

Additional file 3 provides details on interventions and outcomes reported in the included studies. This section provides a narrative synthesis of the evidence. First, we conducted a preliminary synthesis of the findings of the included studies, grouped according to targeted care.
Then, we explored the relationships among the characteristics of the individual studies, their reported findings, and the findings of different studies.

We grouped the interventions according to targeted care as follows: promoting healthy life styles $(n=6)$, dispensing non-prescription medications $(n=4)$, dispensing prescription medications $(n=2)$, drug-related problems $(n=2)$, treatment recommendations $(n=2)$, and use of medical devices $(n=1)$.

The promotion of healthy lifestyles group involved intervention-targeted pharmacist counselling concerning smoking cessation $(n=3)$, sexually transmitted diseases $(n=2)$, and skin cancer prevention $(n=1)$. The interventions involved educational meetings supplemented with educational materials, outreach visits, and feedback. For smoking cessation studies, patient-reported outcome measures demonstrated an improvement in two studies and no effect in one study. For sexually transmitted diseases [28, 29], simulated patients reported significantly better recognition and management in one study and mixed results in the other. Simulated patients 
Table 4 Professional interventions as per Cochrane EPOC review group (adapted from reference [21])

\begin{tabular}{|c|c|}
\hline Intervention & Description \\
\hline \multicolumn{2}{|c|}{ Category: interventions targeted at healthcare workers } \\
\hline Distribution of educational & $\begin{array}{l}\text { Distribution to individuals, or groups, of educational materials to support clinical care, i.e., any intervention in which } \\
\text { knowledge is distributed. For example, this may be facilitated by the Internet, learning critical appraisal skills; skills } \\
\text { for electronic retrieval of information, diagnostic formulation; question formulation }\end{array}$ \\
\hline Educational meetings & Courses, workshops, conferences, or other educational meetings \\
\hline Educational outreach visits & $\begin{array}{l}\text { Personal visits by a trained person to health workers in their own settings, to provide information with the aim of } \\
\text { changing practice }\end{array}$ \\
\hline Audit and feedback & $\begin{array}{l}\text { Any summary of clinical performance of healthcare over a specified period of time. The summary may also have } \\
\text { included recommendations for clinical action. The information may have been obtained from medical records, } \\
\text { databases, or patient observations }\end{array}$ \\
\hline Clinical practice guidelines & $\begin{array}{l}\text { Clinical guidelines are systematically developed statements to assist healthcare providers and patients to decide } \\
\text { on appropriate health care for specific clinical circumstances (US IOM) }\end{array}$ \\
\hline Local opinion leaders & The identification and use of identifiable local opinion leaders to promote good clinical practice \\
\hline Reminders & $\begin{array}{l}\text { Manual or computerised interventions that prompt health workers to perform an action during a consultation } \\
\text { with a patient, for example computer decision support systems }\end{array}$ \\
\hline \multicolumn{2}{|c|}{ Coordination of care and management of care processes } \\
\hline $\begin{array}{l}\text { Communication between } \\
\text { providers }\end{array}$ & $\begin{array}{l}\text { Systems or strategies for improving the communication between health care providers, for example systems to } \\
\text { improve immunisation coverage in LMIC }\end{array}$ \\
\hline
\end{tabular}

reported significantly improved rates of skin cancer counselling [32] in the intervention group (which received educational videos and onsite feedback on counselling performance) compared with the control group.

The dispensing of non-prescription medication group involved three studies on analgesics $[25,26,36]$ and one study on antifungals [38]. Simulated patient visits were used to assess outcomes in all the studies. The interventions, which included educational meetings, onsite feedback, and protocol, improved significantly the process of non-prescription analgesics counselling. There was no difference in outcomes between the dissemination of an evidence-based guideline for the sale of antifungals by post, educational outreach visits, education meetings, or educational meetings combined with outreach visits.

The studies $(n=2)$ on dispensing prescription medications involved medications such as antibiotics and oral steroids and were conducted in three study sites [23, 24]. The multifaceted interventions involved educational meetings, educational materials, outreach visits, local opinion leaders, and guidelines. Simulated patients reported reductions in the inappropriate dispensing of medications at two of the three study sites.

Two studies investigated drug-related problems, one in the elderly [31] and the other in kidney disease patients [41]. The outcomes were measured using patient reports and pharmacists' documentation. The interventions had a mixed impact. For example, both studies demonstrated that the pharmacists in the intervention groups interacted more with the patients and intervened more frequently to manage drug-related problems, with no impact on the number of refusals to dispense a medication, patients' knowledge about the drug, adherence, or drug therapy problems.

Two studies examined treatment recommendations. One study used simulated patient visits to measure the impact of educational meeting and educational materials on the number of pharmacist-facilitated asthma plans and on pharmacists' general communication skills using the Global Rating Scale [27]. The other study measured the impact of an electronic decision-support prompt to remind pharmacists to discuss the suitability of aspirin therapy with eligible diabetes patients [35]. Both interventions resulted in positive changes in outcome measures.

One study reported on the improvement in pharmacists' ability to assess and teach correct inhaler technique skills with educational meetings, educational materials, audits, and feedback [22].

Based on the summary above, five studies reported a mixed impact, as some outcomes were favourably changed by the intervention and some outcomes were not changed. The unclear risk of bias in the majority of the studies provides little help in explaining the differences in reported findings among studies. Additionally, we did not observe any differences in the outcomes and the methods used to measure outcomes that could explain variations in the findings. As many of the studies did not perform sample size calculation, one explanation could be that the sample sizes were inadequate for detecting a difference between the intervention and control groups. Interestingly, one study was conducted in two settings using the same interventions, but the implementation of the interventions could explain the differences in effectiveness. For instance, the site at which a negative 
effect of the educational intervention was found was a seminar for large group and a voluntary peer review [23], while the other site involved face-to-face educational intervention and compulsory peer review [24]. This example illustrates how modifications of any intervention during the implementation process might impact outcomes. Furthermore, the pharmacists' attitudes and working conditions may have differed between the two settings. In another study about smoking cessation, the same educational intervention was delivered to pharmacists and physicians separately, and the outcomes were assessed by patient report 12 months after intervention [34]. An increase in helping patients to quit smoking was found in the physicians in the intervention group, but not in the control group. Among the pharmacists, there was no difference between the intervention and control groups. This example suggests that factors other than knowledge and competence might impact outcomes. Examples of these factors include community pharmacists' attitudes towards counselling, work hours, and staffing.

\section{Discussion}

This study provides a review of the literature on interventions for improving pharmacist-led counselling in the community setting. The findings of the included 17 studies suggest that educational meetings combined with outreach visits and feedback have a positive effect on community pharmacists' counselling in the community pharmacy setting. This finding is consistent with previous reviews on interventions for changing healthcare professionals' behaviour [39, 42-44]. Johnson and May [42] conducted a review of systematic review articles to establish the characteristics of successful behavioural change interventions in healthcare. These authors identified 67 reviews examining the following three main categories of interventions: persuasive interventions (e.g. diffuse persuasive strategies, such as marketing and mass media, or direct persuasion strategies, such as local consensus processes and local opinion leaders); educational and informational interventions (e.g. patient-mediated interventions, dissemination of educational materials, educational meetings, and educational outreach); and action and monitoring interventions (e.g. audits, feedback, and reminders). The authors concluded that interventions focusing on actions or education tended to have more positive effects on professional behaviour than those based on persuasion. Several Cochrane reviews have shown that educational meetings [39], outreach visits [43], and audits and feedback [44] can improve professional practices and patient healthcare outcomes; however, the effect is most likely to be small and to vary according to many factors, such as the complexity of the behaviour targeted by the intervention. A previous review identified 11 studies that reported that the use of active learning through training using role play, feedback, and reflection was important for enhancing the communication skills of community pharmacists during consultations regarding non-prescription medications [17]. Another review identified 21 studies that reported that the use of training delivered as either didactic or interactive sessions had the potential to modify community pharmacists' behaviour during service delivery [15].

The studies included in the present review contained insufficient information on methodology to permit judgement of the risk of bias, which necessitates caution in interpreting the findings. The subjective nature of outcome measures and the unclear blinding of outcome assessors also lowered our confidence in the findings. Furthermore, the short-term follow-up period precluded firm conclusions regarding sustained changes in the outcomes resulting from the interventions.

\section{Strengths and limitations}

The present study offers a different perspective on community pharmacists' counselling than was provided in most previous studies. In contrast to previous reviews $[2-4,10,13,14]$, we focused on studies investigating interventions for improving community pharmacist-led patient counselling. We deliberately narrowed the focus of the review to those studies that attempted to measure the impact of the intervention on the pharmacists' behaviour during counselling and in a community setting. Our detailed examination of the types of interventions and assessment of the quality of the included studies provides insight into the strength of the evidence from the included studies and a greater understanding of the gaps in the literature.

Some limitations must be considered. Certain relevant papers may not have been included in our review, such as studies that are not indexed in the searched databases, studies published in languages other than English, and unpublished studies (grey literature). We attempted to ensure that our search strategy was as comprehensive as possible; however, it is possible that some papers describing counselling used different keywords, and in such cases, these papers could not have been identified for this review. There is no single definition of counselling in community pharmacy. Consequently, subjective assessments of study eligibility were required, which might have introduced some bias in the inclusion of studies. We did not contact the original studies' authors to clarify many unreported study characteristics.

\section{Implications for future studies}

The studies included in this review varied in the quality of reporting of study methodology and intervention components. Future studies should report their methods and findings in a comprehensive and transparent 
manner and describe intervention components in sufficient detail to facilitate evaluation and replication by others. We recommend the use of reporting guidelines for describing research and interventions $[45,46]$.

Counselling is a complex process influenced by the pharmacists, the customer, and their interaction [12]. Many factors influence the content and extent of the counselling provided by community pharmacists, including the type of medications (prescription only versus non-prescription medicine), the type of prescription (new versus repeat), type of presentation (product requests, symptoms, or conditions), and time constraints [12, 41, 47]. Pharmacy users' expectations of their visit (i.e. buying a product versus obtaining a professional service) can influence the attempts of the pharmacy staff to engage the users in dialogue about their medicine use [48]. Additionally, pharmacy users' interactions with community pharmacists are influenced by their perceptions of the professional role of the community pharmacist [48]. Furthermore, pharmacy users' awareness of the need for questioning and their willingness to answer questions [49] are important factors. For instance, users may perceive the questions pharmacists ask as an attempt to control their medicine use, may find the dialogue irrelevant, or may not understand the pharmacists' motivation for asking questions [12]. The discrepancies between pharmacy users and pharmacists' expectations regarding illness and medicine have also been suggested as a barrier to optimal counselling [12]. Therefore, interventions should not be restricted to improving the knowledge and communication skills of the pharmacists. Counselling practices can be negatively influenced by the pharmacist's workload, the pharmacy layout, lack of access to the patient's health information, and the patient's expectations of community pharmacists. Promising interventions that could be explored in future studies include delivery arrangements, such as staffing models; the use of information and communication technology; and governance arrangements, such as professional competence, training, and licensing. Future reviews on counselling in community pharmacy should synthesise evidence on interventions that target patients as part of the counselling process.

To identify effective behavioural change interventions, it is important to characterise the interventions [50]. The characterisation of interventions involves matching all possible intervention types to the behavioural target, the target population, the context in which the intervention is delivered, the underlying behavioural model, and the influencing factors [50]. Only six studies indicated the theoretical framework that was used to develop the interventions. We suggest that future studies characterise the interventions by describing the constructs of the framework used and how the constructs were integrated into the design of the intervention and the outcome measurement. Several frameworks for characterising behavioural change interventions exist. The behaviour change wheel is one of the few frameworks that meet all usefulness criteria of comprehensiveness, coherence, and a clear link to an overarching model of behaviour [50].

Future studies may consider examining individual interventions as the use of multifaceted interventions did not allow a clear understanding of the effectiveness of individual interventions. Previous reviews showed no compelling evidence that multifaceted interventions are more effective than single-component interventions in changing healthcare professionals' behaviour [39, 51]. Comparisons of different types of interventions are also recommended.

We observed that the outcome measures in the identified studies were mainly subjective and focused on the quantity rather than the quality of counselling. There is a lack of reliable criteria or instruments for assessing the appropriateness of patient counselling in pharmacy practice. The variability in the outcome measures used among the studies further complicated the assessment of the interventions' effectiveness. Researchers have attempted to describe the criteria used to assess the appropriateness of patient counselling in the community setting $[52,53]$; however, more studies are needed to refine the criteria and establish a reliable instrument that is applicable for use in interventional studies.

Most of the reviewed studies documented changes in outcomes using simulated patient visits, a method that is commonly used in the pharmacy literature to develop and assess communication skills [40, 54]. Future studies should adhere to recommendations to improve the quality and validity of simulated patient visits, such as the use of standard data collection tools and audiotaping, if possible [54].

In the identified papers, we also observed inadequate discussion of the contextual circumstances and factors that can influence the delivery, implementation, and sustainability of the interventions. Factors that are crucial for successful implementation include costs, acceptability, and organisational changes. Future studies should elaborate on intervention implementation and sustainability issues to improve counselling by community pharmacists. For instance, frameworks have been proposed for assessing the acceptability of healthcare interventions during the development, piloting and feasibility, outcome and process evaluation, and implementation phases [55]. Future studies should utilise such frameworks to assess acceptability and facilitate the successful implementation of the interventions. 
In this review, we focused on the effectiveness of interventions targeting counselling in the community pharmacy setting. Future reviews should identify evidence of the cost-effectiveness of these interventions. As the development and implementation of an intervention require a substantial resource commitment, it is important to have evidence on cost-effectiveness to aid decisions regarding resource allocation. This area has been neglected by researchers in this field [56].

\section{Conclusion}

The included studies showed that educational meetings combined with educational materials, outreach visits, and feedback can improve pharmacists' counselling in community settings. However, the unclear risk of bias and poor quality of reporting of intervention components necessitate caution in interpreting the findings.

\section{Additional files}

Additional file 1: PRISMA checklist. (DOC $58 \mathrm{~kb}$ )

Additional file 2: Reasons for exclusion. (DOCX $24 \mathrm{~kb}$ )

Additional file 3: Summary of interventions and main findings of included studies. (DOCX $35 \mathrm{~kb}$ )

\section{Abbreviations}

EPOC: The Cochrane Effective Practice and Organisation of Care

\section{Availability of data and materials}

All the data generated or analysed during this study are included in this published article [and its additional files].

\section{Authors' contributions}

SA conceptualised this review. SA, NA, HA, and AA made substantial contributions to the study design. All the authors contributed to the title screening and abstracting. All the authors provided input and were involved in the interpretation of the results. SA drafted the manuscript. All the authors revised the manuscript. All the authors read and approved the final version.

\section{Competing interests}

The authors declare that they have no competing interests.

\section{Publisher's Note}

Springer Nature remains neutral with regard to jurisdictional claims in published maps and institutional affiliations.

\section{Author details}

'Clinical Pharmacy Department, College of Pharmacy, King Saud University, Riyadh, Kingdom of Saudi Arabia. ${ }^{2}$ Pharmaceutical Care Services, King Abdulaziz Medical City, National Guard Health Affairs, PO Box 376316, Riyadh 11335, Kingdom of Saudi Arabia.

Received: 14 September 2017 Accepted: 11 April 2018

Published online: 02 May 2018

\section{References}

1. Joint FIP/WHO guidelines on good pharmacy practice: standards for quality of pharmacy services. https://www.fip.org/www/uploads/database_file. php?id=331\&table_id=. Accessed 17 Jul 2017.

2. Okumura LM, Rotta I, Correr CJ. Assessment of pharmacist-led patient counseling in randomized controlled trials: a systematic review. Int J Clin Pharm. 2014;36:882-91. https://doi.org/10.1007/s11096-014-9982-1.
3. Puspitasari HP, Aslani P, Krass I. A review of counseling practices on prescription medicines in community pharmacies. Res Soc Adm Pharm. 2009;5:197-210. https://doi.org/10.1016/j.sapharm.2008.08.006.

4. Shah B, Chewning B. Conceptualizing and measuring pharmacist-patient communication: a review of published studies. Res Social Adm Pharm. 2006; 2:153-85. https://doi.org/10.1016/j.sapharm.2006.05.001.

5. Brown TJ, Todd A, O'Malley C, Moore HJ, Husband AK, Bambra C, et al. Community pharmacy-delivered interventions for public health priorities: a systematic review of interventions for alcohol reduction, smoking cessation and weight management, including meta-analysis for smoking cessation. BMJ Open. 2016;6:e009828. https://doi.org/10.1136/bmjopen2015-009828.

6. Horvat N, Koder M, Kos M, Watson M, Skelton J, Bond C, et al. Using the simulated patient methodology to assess paracetamol-related counselling for headache. PLoS One. 2012;7:e52510. https://doi.org/10.1371/journal. pone.0052510.

7. Koster ES, van Meeteren MM, van Dijk M, van den Bemt BJF, Ensing HT, Bouvy ML, et al. Patient-provider interaction during medication encounters: a study in outpatient pharmacies in the Netherlands. Patient Educ Couns. 2015;98:843-8. https://doi.org/10.1016/.jpec.2015.03.007.

8. Kippist C, Wong K, Bartlett D, Saini B. How do pharmacists respond to complaints of acute insomnia? A simulated patient study. Int J Clin Pharm. 2011;33:237-45. https://doi.org/10.1007/s11096-011-9482-5.

9. van Dijk M, Blom L, Koopman L, Philbert D, Koster E, Bouvy M, et al. Patientprovider communication about medication use at the community pharmacy counter. Int J Pharm Pract. 2016;24:13-21. https://doi.org/10.1111/ijpp.12198.

10. van Eikenhorst L, Salema N-E, Anderson C. A systematic review in select countries of the role of the pharmacist in consultations and sales of nonprescription medicines in community pharmacy. Res Soc Adm Pharm. 2016; 13:17-38. https://doi.org/10.1016/j.sapharm.2016.02.010.

11. Schneider CR, Everett AW, Geelhoed E, Kendall PA, Clifford RM. Measuring the assessment and counseling provided with the supply of nonprescription asthma reliever medication: a simulated patient study. Ann Pharmacother. 2009;43:1512-8. https://doi.org/10.1345/aph.1M086.

12. Kaae $S$, Traulsen JM, Nørgaard LS. Challenges to counseling customers at the pharmacy counter-why do they exist? Res Soc Adm Pharm. 2012;8: 253-7. https://doi.org/10.1016/j.sapharm.2011.05.002.

13. Blalock SJ, Roberts AW, Lauffenburger JC, Thompson T, O'Connor SK. The effect of community pharmacy-based interventions on patient health outcomes: a systematic review. Med Care Res Rev. 2013;70:235-66. https:// doi.org/10.1177/1077558712459215

14. Van Wijk BL, Klungel OH, Heerdink ER, de Boer A. Effectiveness of interventions by community pharmacists to improve patient adherence to chronic medication: a systematic review. Ann Pharmacother. 2005;39:31928. https://doi.org/10.1345/aph.1E027.

15. Patwardhan PD, Amin ME, Chewning BA. Intervention research to enhance community pharmacists' cognitive services: a systematic review. Res Social Adm Pharm. 10:475-93. https://doi.org/10.1016/j.sapharm.2013.07.005.

16. Watkins $\mathrm{K}$. Effectiveness of implementation strategies for clinical guidelines to community pharmacy: a systematic review. Implement Sci. 2016; https:// doi.org/10.1186/s13012-015-0337-7.

17. Seubert L, Whitelaw K, Hattingh L, Watson MC, Clifford RM. Interventions to enhance effective communication during over-the-counter consultations in the community pharmacy setting: a systematic review. Res Soc Adm Pharm. 2018. https://doi.org/10.1016/j.sapharm.2017.12.001.

18. Higgins JPT, Green S. Cochrane Handbook for Systematic Reviews of Interventions Version 5.1.0 [updated March 2011]. Cochrane Collaboration. 2011. http://handbook.cochrane.org.

19. Systematic Reviews. CRD's guidance for undertaking reviews in health care. Centre for Reviews and Dissemination: University of York; 2009. https://doi. org/10.1016/S1473-3099(10)70065-7.

20. Moher D, Liberati A, Tetzlaff J, Altman DG, The PRISMA Group. Preferred reporting items for systematic reviews and MetaAnalyses: the PRISMA statement. PLoS Med. 2009;6(7):e1000097. https://doi.org/10.1371/journal. pmed. 1000097.

21. Cochrane Effective Practice and Organisation of Care (EPOC). EPOC resources for review authors, 2018. http://epoc.cochrane.org/resources/ epoc-resources-review-authors.

22. Basheti IA, Armour CL, Reddel HK, Bosnic-Anticevich SZ. Long-term maintenance of pharmacists' inhaler technique demonstration skills. Am J Pharm Educ. 2009;73:1-8. 
23. Chalker J, Ratanawijitrasin S, Chuc NT, Petzold M, Tomson G. Effectiveness of a multi-component intervention on dispensing practices at private pharmacies in Vietnam and Thailand_-a randomized controlled trial. Soc Sci Med. 2005;60:131-41. https://doi.org/10.1016/j.socscimed.2004.04.019.

24. Chuc NTK, Larsson M, Do NT, Diwan VK, Tomson GB, Falkenberg T. Improving private pharmacy practice: a multi-intervention experiment in Hanoi, Vietnam. J Clin Epidemiol. 2002;55:1148-55. https://doi.org/10.1016/ S0895-4356(02)00458-4.

25. De Almeida Neto AC, Benrimoj SI, Kavanagh DJ, Boakes RA. A pharmacy based protocol and training program for non-prescription analgesics. I Soc Adm Pharm. 2000;17:183-92.

26. De Almeida AC, Benrimoj SI, Kavanagh DJ, Boakes RA. Neovel educational training program for community. Pharmacists. 2000;64:302-7.

27. Dolovich L, Sabharwal M, Agro K, Foster G, Lee A, McCarthy L, et al. The effect of pharmacist education on asthma treatment plans for simulated patients. Pharm World Sci. 2007;29:228-39.

28. Garcia P, Hughes J, Carcamo C, Holmes KK. Training pharmacy workers in recognition, management, and prevention of STDs: district-randomized controlled trial. Bull World Health Organ. 2003:81:806-14.

29. Garcia PJ, Gotuzzo E, Hughes JP, Holmes KK. Syndromic management of STDs in pharmacies: evaluation and randomised intervention trial. Sex Transm Infect. 1998;74(Suppl 1):S153-8.

30. Kimberlin CL, Berardo DH, Pendergast JF, McKenzie LC. Effects of an education program for community pharmacists on detecting drug-related problems in elderly patients. Med Care. 31:451-68. https:/doi.org/10.2307/3766079.

31. Lalonde L, Normandeau M, Lamarre D, Lord A, Berbiche D, Corneille L, et al. Evaluation of a training and communication-network nephrology program for community pharmacists. Pharm World Sci. 2008;30:924-33.

32. Mayer JA, Eckhardt L, Stepanski BM, Sallis JF, Elder JP, Slymen DJ, et al. Promoting skin cancer prevention counseling by pharmacists. Am J Public Health. 1998;88:1096-9

33. Patwardhan PD, Chewning BA. Effectiveness of intervention to implement tobacco cessation counseling in community chain pharmacies. J Am Pharm Assoc (2003). 2014:52:507-14. https://doi.org/10.1331/JAPhA.2012.10117.

34. Prokhorov AV, Hudmon KS, Marani S, Foxhall L, Ford KH, Luca NS, et al. Engaging physicians and pharmacists in providing smoking cessation counseling. Arch Intern Med. 2010;170:1640-6. https://doi.org/10.1001/ archinternmed.2010.344.

35. Reeve JF, Tenni PC, Peterson GM. An electronic prompt in dispensing software to promote clinical interventions by community pharmacists: a randomized controlled trial. Br J Clin Pharmacol. 2008;65:377-85. https://doi. org/10.1111/j.1365-2125.2007.03012.x.

36. Sigrist T, Benrimoj SI, Hersberger K. Changing pharmacists' and pharmacist assistants' practice in dealing with direct requests for non-prescription analgesics; 2002. p. 23-9.

37. Sinclair HK, Bond CM, Lennox AS, Silcock J, Winfield AJ, Donnan PT, et al. Training pharmacists and pharmacy assistants in the stage-of-change model of smoking cessation: a randomised controlled trial in Scotland. Tob Control. 1998;7:253-61. https://doi.org/10.1136/tc.7.3.253.

38. Watson MC, Bond CM, Grimshaw JM, Mollison J, Ludbrook A, Walker AE. Educational strategies to promote evidence-based community pharmacy practice: a cluster randomized controlled trial (RCT). Fam Pract. 2002;19:529-36.

39. Forsetlund L, Bjørndal A, Rashidian A, Jamtvedt G, O'Brien MA, Wolf FM, et al. Continuing education meetings and workshops: effects on professional practice and health care outcomes. In: Forsetlund L, editor. Cochrane Database of Systematic Reviews. John Wiley \& Sons, Ltd: Chichester, UK; 2009. https://doi.org/10.1002/14651858.CD003030.pub2.

40. Mesquita AR, Lyra DP, Brito GC, Balisa-Rocha BJ, Aguiar PM, de Almeida Neto AC. Developing communication skills in pharmacy: a systematic review of the use of simulated patient methods. Patient Educ Couns. 2010; 78:143-8. https://doi.org/10.1016/j.pec.2009.07.012.

41. Kimberlin CL, Jamison AN, Linden S, Winterstein AG. Patient counseling practices in U.S. pharmacies: effects of having pharmacists hand the medication to the patient and state regulations on pharmacist counseling. $J$ Am Pharm Assoc. 2011;51:527-34. https://doi.org/10.1331/JAPhA.2011.10012.

42. Johnson MJ, May CR. Promoting professional behaviour change in healthcare: what interventions work, and why? A theory-led overview of systematic reviews. BMJ Open. 2015;5:e008592. https://doi.org/10.1136/ bmjopen-2015-008592.

43. O'Brien MA, Rogers $\mathrm{S}$, Jamtvedt G, Oxman AD, Odgaard-Jensen J, Kristoffersen DT, et al. Educational outreach visits: effects on professional practice and health care outcomes. In: In: O'Brien MA, editor. Cochrane Database of Systematic Reviews. John Wiley \& Sons, Ltd: Chichester, UK 2007. https://doi.org/10.1002/14651858.CD000409.pub2.

44. Ivers N, Jamtvedt G, Flottorp S, Young JM, Odgaard-Jensen J, French SD, et al. Audit and feedback: effects on professional practice and healthcare outcomes. In: In: Ivers N, editor. Cochrane Database of Systematic Reviews. John Wiley \& Sons, Ltd: Chichester, UK; 2012. https://doi.org/10.1002/ 14651858.CD000259.pub3.

45. Schulz KF, Altman DG, Moher D, Group C. CONSORT 2010 statement: updated guidelines for reporting parallel group randomised trials. PLoS Med. 2010;7:e1000251. https://doi.org/10.1371/journal.pmed.1000251.

46. Hoffmann TC, Glasziou PP, Boutron I, Milne R, Perera R, Moher D, et al. Better reporting of interventions: template for intervention description and replication (TIDieR) checklist and guide. BMJ. 2014;348:1-12. https://doi.org/ 10.1136/bmj.g1687.

47. Svarstad BL, Bultman DC, Mount JK. Patient counseling provided in community pharmacies: effects of state regulation, pharmacist age, and busyness. J Am Pharm Assoc. 2003;44:22-9.

48. Sabater-Galindo M, Ruiz de Maya S, Benrimoj SI, Gastelurrutia MA, MartínezMartínez F, Sabater-Hernández D. Patients' expectations of the role of the community pharmacist: development and testing of a conceptual model. Res Soc Adm Pharm. 2016;13:313-20. https://doi.org/10.1016/j.sapharm. 2016.04.001

49. Morris CJ, Cantrill JA, Weiss MC. "One simple question should be enough": consumers' perceptions of pharmacy protocols. Int J Pharm Pract. 1997;5: 64-71. https://doi.org/10.1111/j.2042-7174.1997.tb00887.x.

50. Michie $S$, van Stralen MM, West R. The behaviour change wheel: a new method for characterising and designing behaviour change interventions. Implement Sci. 2011;6:42. https://doi.org/10.1186/1748-5908-6-42.

51. Squires JE, Sullivan K, Eccles MP, Worswick J, Grimshaw JM. Are multifaceted interventions more effective than single-component interventions in changing health-care professionals' behaviours? An overview of systematic reviews. Implement Sci. 2014;9:152. https://doi.org/10.1186/s13012-014-0152-6.

52. Lin H-W, Pickard AS, Mahady GB, Karabatsos G, Crawford SY, Popovich NG. An instrument to evaluate pharmacists' patient counseling on herbal and dietary supplements. Am J Pharm Educ. 2010;74:192.

53. Ward PR, Bissell P, Noyce PR. Criteria for assessing the appropriateness of patient counseling in community pharmacies. Ann Pharmacother. 2000;34: 170-5. https://doi.org/10.1345/aph.19135.

54. Watson M, Norris P, Granas A. A systematic review of the use of simulated patients and pharmacy practice research. Int J Pharm Pract. 2006;14:83-93. https://doi.org/10.1211/ijpp.14.2.0002.

55. Sekhon M, Cartwright M, Francis JJ. Acceptability of healthcare interventions: an overview of reviews and development of a theoretical framework. BMC Health Serv Res. 2017;17:88. https://doi.org/10.1186/s12913-017-2031-8.

56. Brown CA, Belfield CR, Field SJ. Cost effectiveness of continuing professional development in health care: a critical review of the evidence. BMJ. 2002;324: $652-5$.

Ready to submit your research? Choose BMC and benefit from:

- fast, convenient online submission

- thorough peer review by experienced researchers in your field

- rapid publication on acceptance

- support for research data, including large and complex data types

- gold Open Access which fosters wider collaboration and increased citations

- maximum visibility for your research: over $100 \mathrm{M}$ website views per year

At BMC, research is always in progress.

Learn more biomedcentral.com/submissions 